\title{
Change of Discourse Type in a Social Activity
}

\author{
* Dr. Shahzada Qaisar, Associate Professor \\ ** Dr. Maria Shiraz, Assistant Professor (Corresponding Author)
}

\begin{abstract}
In this study, we propose classroom discourse as a dynamic activity whereby the discourse shifts from one mode to another within one social activity when students are involved to complete the task. The data for this study consisted of audio and video-recordings of the sessions. The analysis transcribed verbal and non-verbal behaviors of the students emerging during social activity. In the analysis, a transcript of one whole episode was taken from a larger study of the data set to inform about the discourse type used by the students during the social activity. The purpose of selecting one episode was to show the change in different types of discourse during a session. The finding of the study implies that in the context of social activity exploratory type discourse is required for learning. This study agrees with the general genetic law of cultural development that links the social, psychological, and cultural aspects during collaborative activities.
\end{abstract}

Keywords: Discourse, Social, Collaborative, Group Work, Exploratory

\section{Introduction}

In this article, we focus on the use of talk by children as a social mode of thinking and as a medium for their education. We put forward how this talk changes during social activity when children are working together in the mathematics classroom. We also deal with some of the issues of methodology, suggesting that new tools are needed for the investigation of the role of spoken language and joint activity in collaborative learning. The tools should address the ways that intersubjectivity is pursued through dialogue, and which allow applied educational researchers to evaluate the quality of the collaborative activity. The results of this classroom-based study are used to illustrate the utility of our conception of exploratory talk as educationally productive talk, and to demonstrate how qualitative method of analysis can contribute to this field of investigation.

\section{Methodology}

The study is using the qualitative and interpretative approach to analyze the phenomena under investigation. One fundamental way to carry out qualitative research is the case study method which involves an empirical investigation of a particular contemporary phenomenon within its real-life context using multiple sources of evidence (Robson, 2020). For this research, we are employing the case study method in which the focus does not lie on individuals, but on the social and cultural phenomenon of student-student interaction that the individuals perform during social activity.

\section{Selection of Participants}

This study is based on purposeful sampling in which the selection of the participants is controlled by the needs of the study and its emerging analysis (Morse \& Richards, 2002, p. 74). For this purpose, two convenient primary schools have been chosen. One school (the Light campus) is taken from 'the Hallmark' network of schools. The second school (the new school) is taken from a different school chain. This chain of schools is working under a non-profit organization working countrywide in Pakistan to improve education, health, civil society, and economic development. Both schools are located in a large city in the province of Punjab, Pakistan. The schools are mixed-gender and their medium of instruction is English but students speak predominantly in the Urdu language when they interact with one another or with teachers. However, mathematics textbooks are in English.

Teachers

Volunteer teachers were chosen to participate in this study; one teacher was selected from each school. In one school 'the Light campus', one of the researchers acted as a teacher and implemented the prepared material. While in the second school 'the new school', the researchers

* University of Education, Lahore Email: qaisarshahzada@yahoo.com

** Kinnaird College for Women, Lahore Email: shirazmaria@ gmail.com 
collaborated with the project teacher and helped him to implement the content.

Grade

The research focus is on the upper primary level (up to grade 5) and we were interested to take grade 5 students (highest primary level in Pakistan. However, the concerned schools hesitated to cooperate in this regard because there is an external examination of grade five students conducted by the Board (a government external assessment body). Therefore, we selected grade four students for this study and follow the school schedule of teaching those topics given in the defined scheme of study.

\section{Data Collection}

\section{Observations: video recording}

This study aims to capture the students' dynamic interaction inferred from their verbal and non-verbal behavior during joint mathematical activities as it happens in a real situation. By analyzing interactions afterward, the research aspires to give a descriptive account of the types of discourse exchanged between students during Collaborative Group Work (CGW) in the selected cases. This technique provided a permanent and complete record of the children's verbal interaction and nonverbal actions in detail and consequently enabled the re-examination of the data using slow-motion facilities necessary for the construction of the transcripts. Moreover, video recordings of the gesture, facial expressions, and tone of the speakers' voice provide access to the fine details of conduct, both discourse, and bodily comportment, to be taken into account while analyzing the meanings and functions underlying children's language use.

Moreover, video recordings provided a live version of the data that allows developing a database that can be used for different concerns and interests. Videotaping the intended lessons in this study achieved many of the mentioned advantages. Students' verbal and non-verbal behavior, which emerged from their interaction during CGW, and the visual contextual features have been transcribed effectively by replaying the videos. We took field notes to keep a record of the activities and curriculum content of each classroom and the kind of materials and information resources children used during CGW.

Analysis

We aimed to look for the types of discourse particularly exploratory discourse on the part of the students. The analysis was to transcribe the verbal and non-verbal behaviors of the students emerging during social activity. We transcribed all the video recorded episodes. The transcripts were parsed into turns; each defined as segments of the speaker's continuous speech. If the speaker did not stop talking even though someone else was speaking, then all of the content was considered to be part of that same turn. If another speaker interrupted then the turn was considered over. Attentive responses such as 'yes', 'umm' and so on, were also considered as turns. The speaker utterances were numbered in which an uninterrupted utterance by one speaker was assigned a natural number. The transcriptions were originally produced in Urdu and then were translated into English. During the translation, careful attention was paid to find equivalent words and phrases. The intention was to ensure that the content of the original Urdu utterances was retained through translation. We were aware that some wrongly translated words could affect the interpretation of the type of discourse of the students. To ensure the validity of translation, we asked a bilingual friend to do the translation and afterward, we compared his translated text with our translated text. The translation of the exchanged discourse could not be done in isolation from the context, because we thought it would be difficult for any other individual (even with a scientific background) to understand without the context. The unit of analysis is an 'episode'. "An episode is a period of time during which an individual or problem-solving group is engaged in one large task" (Schoenfeld, 1985, p. 292).

\section{Analytical Framework}

This part describes Mercer's (1995) framework which is adapted for this study as a starting point to serve the purpose of the present investigation by delineating explicitly the type of discourse that occurs as individuals work with others in a small-group setting. It tries to investigate how children use discourse to think together. The framework shows the different types of discourse of the students during the social activity. It takes into account social, discursive, and cognitive processes and their interactions. It comprises three distinct modes of discourse that characterizes different ways of talking and thinking together (Mercer 1995, 1996). The framework attempts to analyze the quality of discourse emerging in student-student interaction when working collaboratively on the task.

\section{Disputation Discourse}


This discourse is characterized by an unwillingness to take the other's point of view and the consistent reassertions of one's own. This type of discourse can be archetypal in form and can consist of 'yes it is - no it isn't' exchanges, commands and parallel assertions. It is a 'disputation' discourse and is associated with competitive activity and individualized decision making. It makes joint activity into a competition rather than a collaborative endeavor. Information is flaunted rather than shared. Students work individually on the task within the group, they disagree with each other and take an individualistic decision. Differences of opinion are opposed rather than resolved, and the general orientation is defensive. Participants work to keep their identities separate and protect their individuality.

\section{Cumulative discourse}

In this type of discourse, students take part in the discussion and elaborate (add information) or confirm the ideas. They share their knowledge and understanding in a supportive and uncritical way. However, new ideas are not developed, just accumulated. There is only routine execution of task and students' activity is product oriented. Students dictate words to be written or repeated what has been said. Students assist one another during group work but there is no reasoning from the person who is helping or any argument from the person who is seeking help.

\section{Exploratory Discourse}

Exploratory discourse refers to discourse in which partners engage critically and constructively with each other. In the joint activity, students explain the ideas to their partners with reasoning. When students are faced with cognitive conflicts, they are resolved rationally. Relevant information is suggested for joint consideration. Students are not only involved in planning or proposing the strategy for doing mathematics but also give the reasons for choosing this. Proposals may be challenged and counter-challenged but; if so, reasons are given and alternative hypotheses are offered and justified; students are engaged.

The discourse of the students during social interaction is an intellectual activity. We are concerned to understand the students' cognitive engagement through discourse, which can be supportive of the students' learning and development and evidence of the success of the activity. This framework supports our understanding of the discourse of participants, that is, to what extent they are at any stage; behaving cooperatively or competitively, and engaging in the critical reflection or the mutual acceptance of ideas (Mercer, 2005). Both cumulative and exploratory discourse seems to promote consensus while disputation discourse does not. Exploratory discourse is more effective for solving problems than the other two (Mercer, 1996). In the analysis, we did not select the pieces of the transcript from any episode to inform about the discourse type of students used during CGW but we are considering the transcript of the whole episode. The purpose to transcribe the whole episode is to analyze the discourse as it moves from one type to another type and the analysis seeks to reveal the factors involved in the shift of discourse from one type to another.

\section{Results \& Discussion}

We have taken one episode from a larger study of data set of 19 episodes to show how discourse moves from one type to another.

\section{i. $\quad$ Setting the task}

The task 'sum and difference' (see appendix 1) were given to the students. The task comprised of a series of questions with apparently the same multi-step structure. It was supposed that the students could develop their own approach by collaborative work, which should be based on reasoning, and not on procedures only. Questions (5) and (6), required a degree of flexible thinking, and question (8), where the solution is $7 \frac{1}{2}$ and $12 \frac{1}{2}$ could likely require students to revise their approach. The last question (9) was intended partly to keep the quicker students busy. The teacher introduced the task by reminding the students of the meanings of words, 'sum' and 'difference'. For this, the teacher used examples such as, what is the sum of 12 and 15 . What is the difference between 12 and 15? After that, a worksheet containing 8 questions was given to each group of three students. 


\section{ii. $\quad$ Transcript of episode E-8, Task: sum and difference}

\section{Table 1}

Transcript of episode

\begin{tabular}{|c|c|c|}
\hline No & Speaker & Discourse \\
\hline 8.1. & Abdul & $\begin{array}{l}\text { Add [the numbers], It [should] be } 24 ; \\
\text { (Abdul touches Larab by his hand to make him attentive) 'ooh'; } \\
\text { Find such [type of two] numbers. }\end{array}$ \\
\hline 8.2 . & Larab & Plus ... 'hum' \\
\hline 8.3 . & Abdul & wait a sec ... 14 and 10 \\
\hline 8.4 . & Larab & 'ooh', yeah, 10 and14 (Larab looks towards Mehak to get her opinion) \\
\hline 8.5 . & Mehak & Yeah; 10 and 14 ( shaking her head in agreement) \\
\hline 8.6. & Abdul & No ...20 and 4 (shaking his head in wondering); No, No, No \\
\hline 8.7. & Larab & 12 and 12 [might be ] \\
\hline 8.8 . & Abdul & wait for one sec. (He writes on the worksheet) \\
\hline 8.9. & Larab & 12 and 12 would be 24 \\
\hline 8.10 . & Abdul & (getting angry) what are you saying? \\
\hline 8.11. & Mehak & $24 \ldots$ and 4 \\
\hline 8.12. & Abdul & what did I say... we should find such numbers after adding and \\
\hline
\end{tabular}
subtracting from the same numbers.

8.13. Larab

'ooh" we are to find such type of two numbers if we add them it should be first (putting the finger on 24 in the question) and by subtracting the same number, it should be (putting the finger on second number in the question); for example $8+2=10$ and $8-2=6$

\begin{tabular}{|c|c|}
\hline 8.14 . & Mehak \\
\hline 8.15 . & Larab \\
\hline 8.16. & Abdul \\
\hline 8.17. & Larab \\
\hline 8.18. & Abdul \\
\hline 8.19. & Mehak \\
\hline 8.20 . & Larab \\
\hline 8.21 . & Abdul \\
\hline 8.22 . & Larab \\
\hline 8.23 . & Abdul \\
\hline 8.24 . & Teache \\
\hline 8.25 . & Mehak \\
\hline 8.26. & Abdul \\
\hline 8.27. & Larab \\
\hline 8.28 . & Mehak \\
\hline 8.29 . & Abdul \\
\hline 8.30 . & Mehak \\
\hline 8.31 . & Larab \\
\hline 8.32 . & Abdul \\
\hline 8.33. & Larab \\
\hline 8.34 . & Abdul \\
\hline 8.35 . & Larab \\
\hline 8.36. & Mehak \\
\hline 8.37. & \\
\hline 8.38 . & Mehak \\
\hline 8.39 . & Abdul \\
\hline
\end{tabular}

Yeah; It is

add 12 and 12, it would be 24

'ooh'; are you blind?

It is necessary to solve the problem, otherwise it will be our insult

If you people will concentrate then we can do

you are 'learned'[unintelligible](?) students, now do it

For God's sake! do it!

I am also doing the same thing; do it

$36 \ldots$

'ooh' are you blind? I am not asking you to add these numbers[given in the question statement]; answer is written already, we should find question ... [unintelligible]

try it, you can solve it

19 and 5 is 24

But ... ( after counting on his fingers); No

adding 4 in 20 are 24

I am saying, you have already told us [about this pair]

I tell you, 'you are not learned [intelligent] students' if we draw out 4 from 20 then it would be ...

Put your copy down [on the table] and write neatly... 17 and 7, but if 7 is subtracted from 17 then it is 10 .

All the pairs, when we add then answer is 24 but when we subtract ... (Mehak is counting on her finger)

(in the meanwhile Abdul cries); subtract 6 from $18 \ldots$

(Larab and Mehak both start counting on their fingers)

12

(Abdul cry with joy), I done it ... 18 and 6

It is done (waving his arms in the air); Yeeees

What are you doing?

... We are great. (?)

Abdul, what do you eat?

Food; do no waste time now, and go ahead to solve the next one

(he is reading the statement),

by adding, it should be 37

8.40. Larab

And, by subtracting it should be 1 ;

As we subtract 4 from 5 then it is 1 .

Can you solve it? 


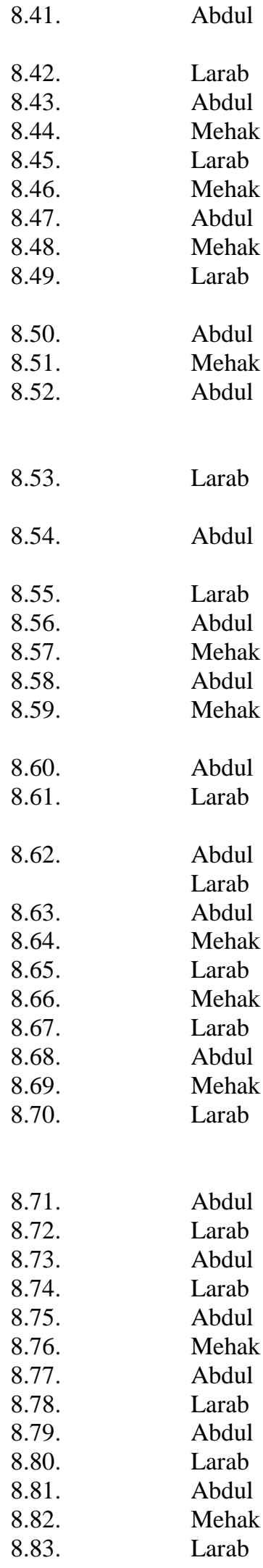

8.84 .

Abdul
Yes I can

stop; stop 28 and 29 (counting on his fingers)

No (he adds on his copy)

then think another one

17 can come

I think 18 and 19 should be there

If we subtract 18 from 19 then the remainder is 1

Yes, it is ... I know 18 can be subtracted from 19

Now we add 18 and 19

37.

(Larab is counting on his fingers)...37; add 8 and 9 is 17,1 , and 2 is 3,

(with joy screams) 'ooh'

It is 37, 37, 37 (she is crying out)

(Crying with happiness) We have done.

(Start to read the statement of next question),

By adding, it should be 42 and by subtracting, it should be 16 .

(As Abdul finish, Larab says without thinking);

26 and 26 ...

Ok, let me add; one second, let me add, let me concentrate!

(Mehak signals to Larab to be silent)

He is looking mad (Abdul is writing)

I am mad, did you not know it before?

(Abdul is counting on his fingers) what are you doing?

I forgot again, what was I thinking?

22 and 22 but ...(she became silent herself),

(She says) if we add 24 and 17 it is 41

Subtracting 17 from 24

Five ... 7 from 15 it is 8 ; do like that, here write 27 and then here 15 ; now subtract it

5 from 7 is 2 and 1 from 2 is 1

Is it not 28 (thinking) 28 is ... (look after solving)

(He replaced 28 with 27 and solves)

21 and 21 is also 42

But ... by subtracting it!

Zero

But how much needed -6 think more

It is 8 as I subtract 17 from $25 \ldots$ but it is wrong

Please look here

Where?

(No more space to write on this page, Mehak gave the page to Larab.

He starts to write on it)

What are you adding? do you not know in this way, it is 32 .

If we subtract, 14 from $20, \ldots$ No, my friend!

Subtract 12 from 18

[unintelligible]

If we added 25 and 17 what is the answer?

42; yes

But, By subtracting 17 from 25 it is 8 which is wrong

If we write 24

Yes friend (?); 24! and here 18

Subtract 18 from 24

It is 6 ; add it $\ldots(24+18=42)$

It is done at last

Done - done ...

(reading the statement of the next question)

Adding ... 100 and subtracting 0

50 and 50; subtract 50 from 50

(shaking his hand in the air) fifty-fifty

great; we have done it (happily says) we have found the answers; tell us the next question, Please Mehak 


\begin{tabular}{|c|c|c|}
\hline 8.85 . & Mehak & Okay! (reading the statement of Q. 6) 92 and 92 \\
\hline 8.86. & Abdul & Same numbers \\
\hline 8.87. & Mehak & I got it [unintelligible] \\
\hline 8.88. & Abdul & $\begin{array}{l}\text { It seems a bit difficult but we will solve (In the meanwhile the period is } \\
\text { over, students ask the teacher to please request the science teacher spare } \\
\text { some time from her period) [it happens in the school that if topic is not } \\
\text { going to finish one teacher can request to another teacher to spend more } \\
\text { time] }\end{array}$ \\
\hline 8.89 . & Mehak & $\begin{array}{l}\text { Teacher, now we are enjoying, and } \ldots \text { and period is over } \\
\text { (attentive towards question) By adding } 50 \text { and } 42, \text { it is } 92\end{array}$ \\
\hline 8.90 . & Abdul & $\begin{array}{l}\text { By adding ... It should be zero... Can we add zero? } \\
\text { (asked the teacher) } \\
\text { (Teacher nods) } \\
\text { Then yes by adding } 0 \text { and } 92 \text { is } 92 .\end{array}$ \\
\hline 8.91. & Mehak & (smiling) Yes, by subtracting zero, it is 92 \\
\hline 8.92 . & Mehak & It is very easy, yes; it is done \\
\hline 8.93. & Larab & $\begin{array}{l}\text { Next question 'by adding [ such two number there should be ] } 73 \text { and by } \\
\text { subtracting it should be } 61\end{array}$ \\
\hline 8.94. & Abdul & [If we] subtract 61 from 73 it is 12 \\
\hline 8.95 . & Mehak & We add 10 in 63 then ... \\
\hline 8.96. & Abdul & It is 73 , but by subtracting it is 53 . \\
\hline 8.97. & Mehak & Yeah, it should be 61 \\
\hline 8.98. & Abdul & 8 and $65 \ldots$ No...I think by adding 6 and 67 \\
\hline 8.99. & Mehak & (counting on his fingers) sixty-eight sixty-nine... seventy-three \\
\hline 8.100. & Abdul & It is done \\
\hline 8.101. & Mehak & Yes it is \\
\hline
\end{tabular}

\section{iii. $\quad$ Turn by turn analysis}

After the initiation made by Abdul when he suggested a pair (turn, 8.3), Larab and Mehak agreed with him without arguing (turns 8.4 and 8.5). In the next turn (8.6), Abdul rejected his own previously suggested pair. He proposed another pair but later, rejected it too without giving any reason. On the other hand, neither Mehak nor Larab asked about the causes of the rejection of these two pairs. Larab proposed a pair (turn 8.7), Abdul started to calculate by writing it on the page; Larab repeated the same pair (turn 8.9). In the meanwhile, Abdul found it was wrong and screamed 'what are you saying' (turn 8.10). On the other hand, Mehak entered the discussion by proposing a very illogical pair (turn 8.11). The discourse had degenerated into a disputation exchange. This was typical during students' interaction that although they attended to each other's suggestions still they were unable to understand the processes; that is, sum and difference apply at the same time.

Abdul realized that the rest of the group members could not understand the question and were considering only the addition process. The sequence shows that students could not take into account the subtraction part while suggesting the pair. Consequently, they were making mistakes. Abdul repeated and explained the question to his group mates (Mehak and Larab). As a response, Larab, not only became acquainted with it but also elaborated on what to do by offering an example (turn 8.13). Mehak agreed with him (turn 8.14). It illustrates that when students implicitly make out what things their group mates did not understand during group work, they tried to make them understand it by repeating and elaborating the missing parts, as Abdul did. From turns 8.16 to 8.21, students were offtask but they were motivating each other. Sometimes 'off-task' behavior could be important to the students to establish good relationships and motivate each other to get effective 'on-task' activities and results (Mercer, 2004; Wegerif, 2005). The teacher intervened and encouraged students by saying 'try it, you can solve it' (turn 8.24). These comments led students to work more effectively than before. For example, Mehak not only suggested a pair but also pointed out to Larab when he repeated the previously proposed pair (turn 8.28). From here, the importance of the role of teachers could be understood, as the teacher's encouragement made students responsible learners and they started sharing their opinion in the joint activities. Mehak praised her groupmates by saying, 'you are learned students' (turn 8.19). Similarly, when they could not find the required pair, Abdul repeated Mehak's sentence in negative form, 'you are not learned students' (turn 8.29). The purpose of repeating the motivational sentences within group work was to keep students on task or asking them indirectly to participate in the thinking and learning processes (turn 8.29). Students respected the suggestions of 
one another during group work and listened attentively when one of them focused on an important point. Larab emphasized that they should be careful about the subtraction process because they had learned from their experience that they were mostly wrong in finding the answer when they were ignoring the subtraction process. Therefore, Mehak not only suggested another pair (turn 8.30) but also subtracted it at the same time. All students were very careful about the subtraction process. For example, Abdul asked to subtract the pair (6 from 18) as he proposed it (turn 8.34). This manifests that students were constructing their knowledge by the collaborative work to understand and solve questions. Larab subtracted and cried '12' (turn 8.33) out of excitement. The collaborative group works intrinsically motivated the students when they developed a new strategy and reached the conclusion. They were looking very happy and confident to solve other tasks as well. Furthermore, they were taking the responsibility to complete the task on time. For example, one of them said, 'Do not waste the time and go ahead' (turn 8.39). Turns from 8.39 to 8.50 notified that the students had now created a joint understanding of the situation from a mathematical point of view. Thus, they were not taking much time to solve the next parts of the worksheet. Moreover, the joint activity helped students to develop the strategy for other sums too. Students were using cumulative discourse to share information and planning. In collaborative work, if one tried to dominate others, then there was a chance to turn the discourse differently. For example, in turn, 8.53 Larab suggested a pair without thinking, just to become prominent in the group. This type of behavior caused an exchange of some unfriendly words (turns 8.55 to 8.56). Abdul did not agree or disagree at once and started counting before concluding (turn 8.54). This dispute was settled when Mehak interrupted, 'What are you doing' (turn 8.57).

Turns from 8.59 to 8.75 , show that students worked collaboratively; they discussed various options, and reminded relevant information to one another. This was the period where students justified their proposals and gave their reasoning. However, their reasoning was focused on procedural issues. This sequence (turns 8.64 to 8.80) of the episode has explicit characteristics of exploratory talk. Students took help not only from one another but also from the previous work to conclude (turn 8.75). Students made explicit references to their talk requiring joint decision-making and tried to organize the interaction so that everyone's ideas were heard. Finally, because of their collaborative effort and supportive behavior, they found the required pair (turn 8.81). Larab read the statement of the next question and as he finished doing it, he proposed the pair and confirmed its answer very quickly by adding and subtracting. It was an easy question and was solved very quickly. The idea of how to solve it came into Larab's mind from a TV commercial in Pakistan that promotes a biscuits brand named 'fifty-fifty'. It can be seen as an example of learning from culture. Turns from 8.83 to 8.89 showed that students had created a joint problem space. The reason for this could lie in the fact that they understood and solved the task collaboratively. Abdul's expression "this is a bit difficult but we will solve them" (turn 8.88) was evidence to accept the challenge.

\section{iv. Summary}

The above-mentioned episode shows the interactive dynamic behavior of the focus group of three students Abdul, Larab, and Mehak during their work on the designed task. The data shows that the students' discourse during social activity was coherent and collaborative in nature in which turns were woven closely together. A difference was observed among students' cognitive strategies, whereas Mehak and Larab seemed to agree more often with the ideas and suggestions created at the beginning but their behavior was different in the middle and at the end of the task. The difference may have been due to not understanding the task at the beginning. Students' discourse, in the beginning, was disputation, cumulative in the middle, and exploratory towards the end (turns 8.64 to 8. 80). In the final section, students participated actively and suggested many strategies to solve the sums with the help of comments and advice on each other's actions. The analysis of the complete dynamic social interaction of group members shows that students were task-oriented and interested to complete the task. Furthermore, the language was being used as a tool to develop collective understanding and thinking more effectively by the students during the activity. Moreover, the group interaction of the students was collaborative and every member of the group participated almost equally, reflecting mutual understanding, which was an element of productive group work. However, in the joint meaning-making, students exposed their incorrect ideas. They did not offer reasoning for their statements and as a result cumulative type discourse emerged. In this session, there was a lot of discourse and it was almost all on task with very few sentences showing off-task behavior. However, 
off-task behavior served the purpose of motivating the students. Students also made suggestions and evaluated their fellow's work. They confirmed and validated each other's statements explicitly (ooh, yeah, it is) or implicitly by repeating them. They clearly enjoyed working together, but they rarely challenged each other during their collaborative work (only at one place a student was challenged; turn 8.40). They neither explained their reasons nor justified to each other, but on the other hand, the strategies and solutions were jointly created and tested, reflecting intensive task engagement.

\section{A discussion on the analysis of episode}

Concerning this episode, we present points about how the discourse was disputation among students at the beginning of the episode and present the reasons which seemed to make possible a shift of discourse into another mode; the cumulative. After that, we discuss the shift of discourse to the next mode; the exploratory. In the end, we briefly highlight how the students used a cultural artifact to develop their thinking.

\section{a. The discourse is disputation}

The analysis of transcripts shows that the discourse was disputation among students at the beginning of the episode because students were sitting in groups but they were not involved in doing mathematics together. They could not develop mutual understanding among themselves. Their discussion was not based on logical reasoning. They did not ask any argumentative questions from each other when one of them suggested any solution. For example, when Abdul suggested a solution pair, both of the other participants of the group (Larab and Mehak) neither asked for an explanation or the reasons for his suggested pair nor did Abdul present any reasoning to them. After that, Abdul offered another pair after rejecting the previous one on his own without giving any reasons to his group mates. Similarly, the other students took their turns and suggested their pairs, which were not the result of their collaborative work. It was their individual work said aloud for the sake of personal representation. They did not share their ideas before or after suggesting their pairs to the group members.

\section{b. $\quad$ A shift of discourse into cumulative type}

The discourse entered into the cumulative mode when students realized that they were just offering their pairs without understanding the statement of the problem. This awareness emerged when they started to think and worked collaboratively, read the statement of the problem again for understanding, and after that, they shared their understanding and identified the known and unknown parts. This behavior helped them to find the mistake before suggesting their pair. They found that they were only considering one aspect (addition) of the problem and ignoring the other aspect (subtraction) before proposing their pairs. As Yackel et al. (1991, p. 401) argue when students strive to work collaboratively and communicate their ideas then "opportunities arise naturally for them to verbalize their thinking, explain or justify their solutions, and ask for clarifications". The nature of discourse was cumulative in that their collaboration had improved and they were involved in sharing their strategies. However, it was still lacking in exchange for reasoning. For example, they presented pairs, which were accepted without arguing about them.

Off-task patterns of discourse: Rojas-Drummond and Mercer (2003) note that observational and experimental studies highlight the value of talk during group work but some researchers (Bennett \& Cass, 1989; Galton, Simon, \& Croll, 1980) observe off-task, an uncooperative discourse that is of little educational value during collaborative work. We also observed in this episode that the students were off-task at some places during the group work. However, their off-task discourse consisted of motivational and encouraging statements, which helped collaborative thinking and working later on. We are not saying that off-task behavior is effective for group work, but it may be useful and has educational value if it motivates and encourages the students for collaboration, and can be useful to develop the collaborative consensus when students are facing difficulties in concluding.

Social work provides confidence and intrinsic motivation for learning: Collaborative group work created confidence among students, which proved helpful to solve the problems. As A. Anderson (2008) reported, students feel more confident while working in groups than when working individually on problem-solving. Students were very happy after finding the pairs to solve the problems and this motivated them to develop their joint understanding from a mathematical point of view. Accordingly, they did not spend as much time solving the other parts because they had learned how to develop the strategies by negotiation.

Composition of Group work 'Triad' a better group size': Larab recommended a pair without 
sharing his reasons with his group mates and emphasized that it was the required pair. It seems that he intended to dominate the group. Abdul did not like this behavior, which caused some unfriendly exchanges of words between them. However, it was resolved by the third participant Mehak. An important point to be noted is that if one participant suggests a pair without mutual understanding and negotiation there are chances to detract the students from collaboration. As it happened, however, Mehak's intervention settled the dispute between them. It shows that the size of a group with three participants might be a better choice for social work than pairs because if tension is created between two participants then the third participant might help to improve the situation by giving suggestions or by informing them about their mistake, as Mehak did in this episode, by saying 'what are you doing' with a facial expression (non-verbal behavior) that indicated they were showing inappropriate behavior. As a result, they were back on their collaborative work and appeared more responsible and critical in presenting their ideas. Yackel et al. (1991) argued that once social problems have been temporarily resolved, the interactions that take place give rise to opportunities for learning that result directly from the interactions. Furthermore, it was the attempt from Mehak to resolve the conflict which provided the opportunities for the students to reconceptualize the problem, as Yackel et al. (1991) put it "thus construct a framework for another solution method, and the opportunity to analyze an erroneous solution method and provide a clarifying explanation" (p. 401-402).

\section{c. $\quad$ A shift of discourse into exploratory mode}

It is common for conceptual differences to emerge between the students during CGW because for each student their "own perceptions, facts, assumptions, values, and general understandings of the material differ to a greater or lesser extent from those of others with whom they are interacting" (King, 1999, p. 89). The analysis of this episode indicates that disagreement could be a turning point in the students' discourse, after which the discourse becomes either disputation or exploratory. When they negotiated understanding and meaning by giving reasons to each other; the discourse entered into an exploratory mode which 'mediates each other's learning'. On the other hand, when they just suggested their ideas and could not reach on consensus the discourse they used was disputation, which has less potential for learning.

When disputes lead to exploratory discourse the collaborative work created space for students to think logically and give reasons for the next parts. The results showed that the CGW facilitated children's learning of mathematics through collaboration, problem-solving, consensus-seeking, and genuine attempts to communicate, all of which are part of collaborating to learn (Yackel et al., 1991). The students' criticality and responsive behavior changed the discourse patterns and the discourse entered into the exploratory mode. The students provided scaffolding to assist one another by their previous work and with reasons to reach conclusions and they made explicit references to their talk requiring joint decision-making. The interaction of the students created a space for ZPD in which students negotiated their meaning during joint activities. They tried to organize their interaction so that everyone's ideas were heard. Finally, because of their collaborative effort and supportive behavior, they found the required pairs quickly.

Learning from cultural artifact: Larab read the statement of one question, 'find two numbers that have a sum of 100 and a difference of 0 ' and as he finished doing so immediately proposed the pair, and confirmed its answer very quickly by adding and subtracting. This question was solved very quickly because the idea to solve it came into Larab's mind from a TV commercial in Pakistan, which promotes a biscuit brand named 'fifty-fifty'. We understood his way of thinking when he was shaking his hand as he had seen in the TV commercial. It can be seen as an example of learning from culture. In this learning context, it was the interplay between school mathematics and out of school mathematics (Masingila, Davidenko, \& Prus-Wisniowska, 1996). Students were involved in sharing their personal experiences to construct a common ground for meaning-making. "Knowing and using students' out-of-school mathematics practice is important in school situations because it provides contexts in which students can make connections" (Masingila et al., 1996, p. 194). Masingila, et al. (1996) also say that connection making can enhance learning and practice in both situations and is essential in the construction of mathematical knowledge.

\section{Conclusion}

Students were found to complete the task when they used either cumulative or exploratory type of discourse, but exploratory discourse seemed to have greater potential for promoting reasoning than cumulative because students appeared to do more justification and explanation with each other, and 
this kind of participating behavior is likely to make more effective learners. This study agrees with the general genetic law of cultural development that links the social, psychological, and cultural aspects during collaborative activities. Students learn from the social interaction that helps the individuals to understand and become aware of their thinking processes. This implies that in the context of group work social interaction is very important to learning. Students construct their new knowledge through negotiation within communicating groups and individuals internalize it during collaborative group work. We do not statically look at discourse, but see discourse as dynamic and shifting from one mode to another within one activity when students are involved to complete the task.

\section{References}

Anderson, A. (2008). An Uphill Battle: Incorporating cooperative learning using a largely individualized curriculum.

Bennett, N., \& Cass, A. (1989). The effects of group composition on group interactive processes and pupil understanding. British Educational Research Journal, 15(1), 19-32.

Galton, M., Simon, B., \& Croll, P. (1980). Inside the primary classroom: Other.

King, A. (1999). Discourse Patterns for Mediating Peer Learning. In A. M. O'Donnell \& A. King (Eds.), Cognitive perspectives on peer learning (pp. 87-116): Lawrence Erlbaum.

Masingila, J. O., Davidenko, S., \& Prus-Wisniowska, E. (1996). Mathematics learning and practice in and out of school: A framework for connecting these experiences. Educational Studies in Mathematics, 31(1), 175-200.

Rojas-Drummond, S., \& Mercer, N. (2003). Scaffolding the development of effective collaboration and learning. International Journal of Educational Research, 39(1-2), 99-111.

Mercer, N. (1994). The quality of talk in children's joint activity at the computer. Journal of Computer Assisted Learning, 10(1), 24-32.

Mercer, N. (1995). The guided construction of knowledge: Talk amongst teachers and learners. Clevedon: Multilingual Matters

Mercer, N. (1996). The quality of talk in children's collaborative activity in the classroom. Learning and Instruction, 6(4), 359-377.

Mercer, N. (2000). Words and minds: How we use language to think together. New York: Routledge.

Mercer, N. (2002). Developing dialogues. In G. Wells \& G. Claxton (Eds.), Learning for life in the 21st century: Sociocultural perspectives on the future of education (pp. 141-153). Oxford: WileyBlackwell.

Mercer, N. (2005). Sociocultural discourse analysis: analyzing classroom talk as a social mode of thinking. Journal of Applied Linguistics, 1(2), 137-165.

Mercer, N. (2007). Sociocultural discourse analysis: analyzing classroom talk as a social mode of thinking (Vol. 1, pp. 137).

Mercer, N., \& Littleton, K. (2007). Dialogue and the Development of Children's Thinking A sociocultural approach. New York: Routledge.

Mercer, N., Phillips, T., \& Somekh, B. (1991). Spoken language and new technology (SLANT). Journal of Computer Assisted Learning, 7(3), 195-202.

Mercer, N., \& Sams, C. (2006). Teaching children how to use language to solve maths problems. Language and Education, 20(6), 507-528.

Mercer, N., Wegerif, R., \& Dawes, L. (1999). Children's talk and the development of reasoning in the classroom. British Educational Research Journal, 25(1), 95-111.

Morse, J. M., \& Richards, L. (2002). Read me first for a user's guide to qualitative methods. Thousand Oaks, Calif: Sage Publications.

Masingila, J. O., Davidenko, S., \& Prus-Wisniowska, E. (1996). Mathematics learning and practice in and out of school: A framework for connecting these experiences. Educational Studies in Mathematics, 31(1), 175-200.

Robson, C. (2002). Real-world research: a resource for social scientists and practitioner-researchers (2nd ed.). Oxford: Blackwell Publishers.

Schoenfeld, A. (1985). Mathematical problem-solving. Orlando: Academic Press.

Wegerif, R. (2007). Dialogic education and technology: expanding the space of learning. New York: Springer.

Yackel, E., Cobb, P., \& Wood, T. (1991). Small-group interactions as a source of learning opportunities in second-grade mathematics. Journal for Research in Mathematics Education, 22(5), 390-408. 